\title{
Mesenchymal stem cells in obesity: insights for translational applications
}

\author{
Kenichi Matsushita ${ }^{1}$ and Victor J Dzau ${ }^{2}$
}

Obesity is now a major public health problem worldwide. Lifestyle modification to reduce the characteristic excess body adiposity is important in the treatment of obesity, but effective therapeutic intervention is still needed to control what has become an obesity epidemic. Unfortunately, many anti-obesity drugs have been withdrawn from market due to adverse side effects. Bariatric surgery therefore remains the most effective therapy for severe cases, although such surgery is invasive and researchers continue to seek new control strategies for obesity. Mesenchymal stem cells (MSCs) are a major source of adipocyte generation, and studies have been conducted into the potential roles of MSCs in treating obesity. However, despite significant progress in stem cell research and its potential applications for obesity, adipogenesis is a highly complex process and the molecular mechanisms governing MSC adipogenesis remain ill defined. In particular, successful clinical application of MSCs will require extensive identification and characterization of the transcriptional regulators controlling MSC adipogenesis. Since obesity is associated with the incidence of multiple important comorbidities, an in-depth understanding of the relationship between MSC adipogenesis and the comorbidities of obesity is also necessary to evaluate the potential of effective and safe MSC-based therapies for obesity. In addition, brown adipogenesis is an attractive topic from the viewpoint of therapeutic innovation and future research into MSC-based brown adipogenesis could lead to a novel breakthrough. Ongoing stem cell studies and emerging research fields such as epigenetics are expected to elucidate the complicated mechanisms at play in MSC adipogenesis and develop novel MSCbased therapeutic options for obesity. This review discusses the current understanding of MSCs in adipogenesis and their potential clinical applications for obesity.

Laboratory Investigation (2017) 97, 1158-1166; doi:10.1038/labinvest.2017.42; published online 17 April 2017

Obesity is a complex medical condition characterized by the accumulation of excess body fat. ${ }^{1}$ The rising incidence of obesity has become a major public health problem worldwide, ${ }^{2-4}$ particularly because obesity is a major risk factor for type 2 diabetes, dyslipidemia, hypertension, stroke, and cardiovascular disease. ${ }^{2,3}$ Obesity also increases the risk of certain types of cancer, ${ }^{5,6}$ and has a reported association with some psychiatric disorders. ${ }^{7,8}$ This robust increase in obesity and associated health complications has prompted multiple control strategies including lifestyle modifications, pharmacotherapy, and surgical approaches. However, lifestyle management has limited effects and many anti-obesity drugs have been withdrawn from market due to adverse side effects. $^{2}$ Thus, the most effective therapy for severe obesity is invasive, bariatric surgery, which has its own inherent risks and remains contentious with respect to long-term efficacy and procedural safety. ${ }^{9-12}$

Severe obesity is ascribed to both an increase in adipose cell size and increased adipocyte cell number. ${ }^{13-15}$ Recent evidence suggests that mesenchymal stem cells (MSCs) are a major source of adipocyte generation, with both MSCs in fat tissue and adipocyte progenitor cells originating from bone marrow implicated in adipogenesis in adult animals. ${ }^{16-19}$ MSCs are thus purported to play a vital role in obesity, and have received increasing attention as a new target for therapy. Since exercise suppresses obesity, Rubin et al ${ }^{20}$ tested the hypothesis that low-magnitude mechanical signals would suppress adiposity, not by metabolizing existing adipose tissue, but instead by inhibiting the differentiation of MSCs into adipocytes. The authors demonstrated that 15 weeks of

${ }^{1}$ Division of Cardiology, Second Department of Internal Medicine, Kyorin University School of Medicine, Tokyo, Japan and ${ }^{2}$ National Academy of Medicine, Washington, DC, USA

Correspondence: Dr K Matsushita, MD, Division of Cardiology, Second Department of Internal Medicine, Kyorin University School of Medicine, 6-20-2 Shinkawa, Mitaka, Tokyo 181-8611, Japan or Dr VJ Dzau, MD, President, National Academy of Medicine, 500 Fifth St NW, Washington, DC 20001, USA.

E-mail: kenichi-matsushita@umin.ac.jp orVDzau@nas.edu

Received 22 January 2017; accepted 24 February 2017 
brief, daily exposure to high-frequency mechanical signals, induced at a magnitude well below that which would arise during walking, suppressed adipogenesis by $27 \%$ in C57BL/6 J mice. ${ }^{20}$ They further reported that irradiated mice receiving bone marrow transplants from heterozygous green fluorescent protein $(\mathrm{GFP})^{+}$mice exhibited a $19 \%$ decrease in MSC to adipocyte differentiation after 6 weeks of the low-magnitude mechanical signals, indicating that the formation of new adipose tissue in their models was deterred by inhibiting MSC adipogenesis. ${ }^{20}$ The authors thus suggested that obesity in humans could be prevented by controlling MSC adipogenesis. ${ }^{20}$

The underlying pathophysiology of obesity remains ill defined and studies are ongoing into the potential roles of MSCs in managing obesity, and into their safety and efficacy in the clinical setting. This review discusses current understanding of the relationship between MSCs and obesity and its potential clinical implications.

\section{ADIPOGENESIS FROM MSCS}

MSCs are multipotent cells that can differentiate into a variety of cells of the mesodermal lineage including adipocytes, ${ }^{21}$ and transdifferentiate into specialized cells of the endodermal and ectodermal lineages. ${ }^{22}$ MSCs were also attributed with immunomodulatory properties that could potentially benefit patients who exhibit adverse immune responses from graftversus-host and autoimmune diseases. ${ }^{23-25}$ These multipotent capacities of MSCs and their therapeutic potential has prompted many clinical and preclinical studies of MSCbased therapy for various diseases, with encouraging results reported thus far. ${ }^{26,27}$

On the other hand, the roles of MSCs in obesity remain ill defined, and further understanding of the mechanisms, regulation and outcomes of adipogenesis is crucial for the development of MSC-based treatments for obesity. Although adipogenesis is a multistep process involving many cellular intermediates, for practical purposes it can be divided into two major phases (Figure 1). ${ }^{28-32}$ During the determination phase, multipotent MSCs differentiate into preadipocytes committed to the adipogenic lineage. ${ }^{28-32}$ Following determination, fibroblastic preadipocytes then become spherical mature adipocytes in the terminal differentiation phase. ${ }^{28-32}$ As a result, adipocytes can synthesize and transport lipids, secrete adipocyte-specific proteins, and express the machinery necessary for insulin sensitivity. ${ }^{28-32}$

The mechanisms governing MSC adipogenesis are quite complex, with the major signaling pathways converging to regulate a range of transcription factors such as peroxisome proliferator-activated receptor-gamma (PPAR-gamma) and several members of the CCAAT/enhancer-binding proteins (C/EBPs) (Figure 1). ${ }^{30-34}$ PPAR-gamma is a nuclear hormone receptor and key regulator of adipogenesis, ${ }^{35,36}$ including in vitro adipogenesis from embryonic stem (ES) cells and embryonic fibroblasts. ${ }^{37,38}$ Specifically, Rosen $e t$ al ${ }^{38}$ created chimeric mice derived from wild-type ES cells and cells with a

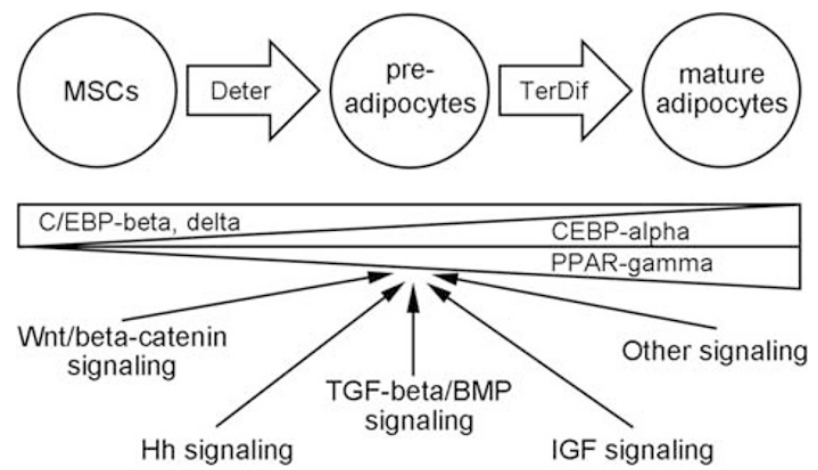

Figure 1 Schematic view of the regulatory mechanisms governing MSC adipogenesis. Adipogenesis can be practically divided into two major phases: the determination phase and the terminal differentiation phase. The former defines the process from multipotent MSCs to preadipocytes, whereas the latter governs how preadipocytes develop into mature adipocytes. The mechanisms underlying MSC adipogenesis are quite complex, with the major signaling pathways converging to regulate a range of transcription factors such as PPAR-gamma and several members of the C/EBP family. PPAR-gamma is considered the master regulator of adipogenesis. C/EBP-beta and C/EBP-delta are recognized to play an important role during the early stage of adipogenesis, whereas CEBPalpha assumes a key role later in the differentiation process. PPARgamma and C/EBP-alpha also operate in a coordinated manner to stimulate adipogenesis. A number of signaling pathways control MSC adipogenesis; however, the full scope of transcriptional control and signaling pathways governing MSC adipogenesis has not been clarified. BMP, bone morphogenetic protein; C/EBP, CCAAT/enhancer-binding protein; Deter, determination phase; Hh, Hedgehog; IGF, insulin-like growth factor; MSCs, mesenchymal stem cells; PPAR, peroxisome proliferator-activated receptor; TerDif, terminal differentiation phase; TGF, transforming growth factor.

homozygous deletion of PPAR-gamma, and used this approach to grow normal tissues from a choice of cells with different genotypes. ${ }^{38}$ By showing exclusion of PPAR-gamma null cells from adult adipose tissues, but not several other of the developed tissues, the authors concluded that PPARgamma is required for adipogenesis in vivo. ${ }^{38}$

The C/EBPs are transcription factors characterized by a highly conserved, basic leucine zipper domain at the $\mathrm{C}$ terminus that facilitates homo- or heterodimerization and DNA binding. ${ }^{35,36,39,40}$ Six members of the family have been isolated and characterized thus far. ${ }^{40}$ Of these, C/EBP-beta and C/EBP-delta are the first transcription factors induced during adipogenesis and play a vital role in directing the differentiation process (Figure 1). ${ }^{39,41}$ On the other hand, CEBP-alpha is induced to assume a key role later in the differentiation process (Figure 1). ${ }^{36}$ The importance of C/EBPs in adipogenesis has been demonstrated in gain- and loss-of-function studies with C/EBP-alpha considered to play the most prominent role, ${ }^{36,39,41}$ by operating with PPARgamma in a coordinated manner to stimulate adipogenesis. ${ }^{35}$ Importantly, PPAR-gamma can promote adipogenesis in C/EBP-alpha-deficient cells; ${ }^{42}$ however, C/EBP-alpha does not function similarly in the absence of PPAR-gamma. ${ }^{43} \mathrm{In}$ 
addition to PPAR-gamma and C/EBP-alpha, other transcription factors interact at various stages of adipocyte differentiation. For example, gene expression profiles using microarray and quantitative reverse transcription polymerase chain reaction analyses of mRNAs isolated from adipocyte differentiation cultures suggested the importance of many transcriptional proteins and receptors for adipogenesis. ${ }^{39,44,45}$

In terms of signaling pathways important for adipogenesis, Wnt/beta-catenin signaling is one of the most important and well studied. ${ }^{46,47}$ Activation of $\mathrm{Wnt} /$ beta-catenin signaling inhibits adipogenesis, ${ }^{48-50}$ whereas blocking endogenous Wnt signaling promotes adipogenic differentiation, ${ }^{49,51}$ suggesting that Wnts act as a brake for adipogenesis. Wnt10b is suggested to be the most important endogenous regulator of adipogenesis, ${ }^{49}$ with transgenic mice overexpressing Wnt10b from the adipocyte-specific FABP4 promotor (FABP4Wnt10b mice) showing reduced adiposity and resistance to diet-induced obesity. ${ }^{50}$ In addition, Wright et al ${ }^{52}$ reported that expressing Wnt10b in the adipose tissue of $o b / o b$ mice using a FABP4-Wnt10b transgene reduced adiposity in these mice. Those authors further demonstrated that Wnt10b protected against genetic obesity in mice due to ectopic expression of agouti $\left(\mathrm{A}^{y}\right) .{ }^{52}$

Recent evidence suggests that Hedgehog (Hh) signaling plays an important role in MSC adipogenesis, with activation of this signaling impairing the differentiation process. ${ }^{53,54}$ Fontaine et $a l^{55}$ also showed that $\mathrm{Hh}$ signaling decreases during adipocyte differentiation from adipose-derived human MSCs, and that activation of $\mathrm{Hh}$ signaling alters adipocyte morphology as well as insulin sensitivity, but inhibition of this signaling was not sufficient to trigger adipogenesis. ${ }^{55}$ In other studies, Suh et $a l^{54}$ showed that inhibiting Hh signaling increased adipogenic differentiation in 3T3-L1 murine preadipocytes, whereas Cousin et $a l^{56}$ found that decreasing Hh signaling was not sufficient to trigger adipogenesis in the same cell type. Thus, while the anti-adipogenic role of $\mathrm{Hh}$ signaling seems to be established, the effect of inhibiting this signaling on adipogenesis remains controversial. ${ }^{57}$

The transforming growth factor (TGF)-beta superfamily exhibits various actions in many cell types including MSCs and adipocytes, with TGF-beta signaling via the bone morphogenetic protein (BMP) ligands shown to regulate adipogenesis. ${ }^{58,59}$ Ignotz et al ${ }^{60}$ further showed that TGF-beta inhibits adipocyte differentiation of 3T3-L1 cells, while Zhou et al $^{61}$ demonstrated that cooperative TGF-beta/Wnt signaling could inhibit adipogenesis in human MSCs. TGF-beta seems to have an anti-adipogenic effects on MSCs, although the effects of BMPs on adipogenesis differ among different cell types and BMP ligands. ${ }^{62}$ For example, BMP2 inhibited adipogenesis in the human marrow stromal cell line hMS, ${ }^{63}$ but promoted adipogenesis in the murine mesenchymal stem cell line $\mathrm{C} 3 \mathrm{H} 10 \mathrm{~T} 1 / 2{ }^{64,65}$ Further, BMP7 promotes adipogenesis in human $\mathrm{MSCs}^{66}$ while BMP4 plays that role in C3H10T1/2 cells. ${ }^{67}$ Further studies are needed to determine the mechanisms by which TGF-beta/BMP signaling affects adipogenesis and the implication for such findings in different cell types.

Finally, insulin-like growth factor (IGF) signaling is also important for adipogenesis. IGF-1 is considered to stimulate adipogenesis, ${ }^{68}$ and Holzenberger et al ${ }^{69}$ demonstrated a strong growth deficit in the fat tissue of mice generated to have very low IGF-1 receptor levels. However, the precise roles and mechanisms of IGF signaling in MSC adipogenesis are still unclear.

The full scope of transcriptional control and signaling pathways governing MSC adipogenesis has not been well defined, and the realization of MSC-based therapeutic strategies for obesity relies on ongoing and future studies to further elucidate these mechanisms.

\section{MSCS AND THE COMORBIDITIES OF OBESITY}

Obesity is associated with multiple comorbidities. One of the strongest associations is with type 2 diabetes, ${ }^{70,71}$ suggesting an important link between this prevalent disease and MSC adipogenesis. While such a link raises the potential of controlling MSC adipogenesis for new disease prevention strategies, there is still much to be learned before we fully understand the role of MSCs in development of type 2 diabetes. Besides the control of adipogenesis, several studies have examined the potential roles of MSCs in treating diabetes (Table 1). For example, MSCs can differentiate into insulin-producing cells, suggesting MSCs as a source of transplantation material in the treatment of diabetes, ${ }^{72-74}$ while other studies demonstrated the angiogenic and anti-inflammatory potential of MSCs in supporting islet transplantation. ${ }^{75,76}$ Furthermore, Dave et al ${ }^{77}$ reported a clinical trial showing that co-infusion of in vitro-generated insulin-producing cells differentiated from autologous adipose-derived MSCs and bone marrow-derived hematopoietic stem cells into the portal circulation, thymus, and

Table 1 Example studies of the relationship between MSC and obesity comorbidities

\begin{tabular}{llc}
\hline Comorbidity & Findings & References \\
\hline DM & MSC as a source of transplantation material & $72-74$ \\
& MSC supports islet transplantation & 75,76 \\
& MSC treatment improves HbA1C & 77 \\
DL & MSC infusion improves DL & 78 \\
& LXR-alpha inhibits MSC adipogenesis & 90 \\
HTN & Pts with HTN exhibit increased circulating MSCs & 95 \\
& Ang II inhibits MSC adipogenesis & 98 \\
& AT 2 R inhibits MSC adipogenesis & 98,100
\end{tabular}

Abbreviations: Ang II, angiotensin II; $\mathrm{AT}_{2} \mathrm{R}$, angiotensin $\mathrm{AT}_{2}$ receptor; $\mathrm{DL}$, dyslipidemia; DM, diabetes mellitus; HbA1c, glycosylated hemoglobin; HTN, hypertension; LXR, liver X receptor; MSC, mesenchymal stem cell; Pts, patients. 
subcutaneous tissue increased serum C-peptide levels and improved glycosylated hemoglobin levels. Significant progress has thus been made in the field of MSC and diabetes, and further research is warranted to realize the clinical potential of MSC adipogenesis in this area.

Dyslipidemia is also a comorbidity of obesity, and while a recent infusion of adipose-derived MSCs improved dyslipidemia in obese mice (Table 1), ${ }^{78}$ the relationship between MSCs and dyslipidemia remains largely unknown. Regarding cholesterol/lipid homeostasis, liver X receptor (LXR)-alpha deserves special consideration. LXR-alpha is an oxysterolregulated nuclear hormone receptor with a central role in cholesterol and lipid homeostasis. ${ }^{79-84}$ Importantly, Gao et a ${ }^{85}$ reported that the chronic activation of LXR by its agonist blocked the development of high-fat diet-induced obesity in mice, suggesting LXR as a potential target for obesity prevention. Accumulating evidence also suggests a direct role for LXR-alpha in adipose tissue, with increased expression of LXR-alpha demonstrated during adipogenesis and high expression levels of LXR-alpha and many LXR-alpha target genes found in adipocytes. ${ }^{45,86-89}$ Although the precise relationship between LXR-alpha and MSC biology remains undefined, we recently reported the role of LXR-alpha in MSC adipogenesis using murine MSCs isolated from the bone marrow of wild type (WT) and LXR-null mice, as well as cell lines stably overexpressing GFP-LXR-alpha or GFP alone, generated from WT murine MSCs by retroviral infection. ${ }^{90}$ Deletion of LXR accelerated adipogenesis in murine MSCs, as determined by lipid droplet accumulation and adipogenesisrelated gene expression, while overexpression of LXR-alpha inhibited adipogenesis. ${ }^{90}$ Because Wnt/beta-catenin signaling is crucial for suppressing adipogenesis, we further examined the effects of deleting LXR or overexpressing LXR-alpha on Wnt expression and cellular beta-catenin levels in the murine MSCs. We found a decrease in both pathway markers in the absence of LXR and an increase in the cells overexpressing LXR-alpha. ${ }^{90}$ Our data thus showed that LXR-alpha has an inhibitory effect on adipogenesis of murine MSCs with Wnt/ beta-catenin signaling (Table 1), ${ }^{90}$ although the clinical relevance of this suppressive effect remains to be explored. Interestingly, Beaven et al ${ }^{91}$ reported increased total body adiposity in LXR-null mice bred onto a leptin-deficient $o b / o b$ background compared with that in WT ob/ob mice. On the other hand, Kalaany et al ${ }^{92}$ reported that LXR-null mice were resistant to diet-induced obesity due to increased energy expenditure. Adipose tissue-specific LXR-null mice have not yet been generated, and hence, the precise roles of LXR in adipose tissue in vivo remain unknown. Further studies are necessary to elucidate the roles of LXR in adipogenesis and clinical obesity.

Another important comorbidity of obesity is hypertension. ${ }^{93,94}$ Marketou et a ${ }^{95}$ reported increased numbers of circulating MSCs in patients with hypertension compared to normotensive patients (Table 1); however, little is known about the relationship between MSC and obesity-associated hypertension. In this context, the renin-angiotensin system (RAS) is of note. The RAS is an endocrine system and considered central in the development of hypertension. ${ }^{96}$ In addition to the circulating RAS, the importance of local RAS at the tissue level is recognized. ${ }^{96,97}$ Previously, we demonstrated that human bone marrow-derived MSCs contain a local RAS and that endogenous angiotensin II (Ang II) production is increased in human MSCs undergoing adipogenic differentiation through increased local renin expression. ${ }^{98}$ We also showed that Ang II inhibits adipogenesis of human MSCs associated with an increase in angiotensin $\mathrm{AT}_{2}$ receptors, ${ }^{98}$ and that pharmacological blockade of these receptors promotes adipogenesis (Table 1$)^{98}$ while inhibiting the osteogenesis of human MSCs. ${ }^{99}$ Recently, we further characterized how the $\mathrm{AT}_{2}$ receptor $\left(\mathrm{AT}_{2} \mathrm{R}\right)$ affects the differentiation of MSCs to adipocytes using a genetic model. ${ }^{100}$ Murine MSCs were isolated from the bone marrow of $\mathrm{AT}_{2} \mathrm{R}$-null mice and wildtype littermates. Compared with MSCs isolated from littermate mice, MSCs from $\mathrm{AT}_{2} \mathrm{R}$-null mice exhibited significantly increased adipogenesis, as determined by lipid droplet accumulation and adipogenesis-related gene expression. ${ }^{100}$ The $\mathrm{AT}_{2} \mathrm{R}$-null group also showed significantly decreased Wnt10b expression accompanied by decreased beta-catenin levels ( $v$ s littermate). ${ }^{100}$ Our results thus revealed that $\mathrm{AT}_{2} \mathrm{R}$ inhibits adipogenic differentiation in murine MSCs via Wnt10b/beta-catenin signaling (Table 1). ${ }^{100}$ These findings suggest an association between MSC adipogenesis and hypertension, based on the central role that the RAS plays in the pathophysiology of hypertension, although such a relationship seems to be quite complex. We also reported that murine MSCs could develop into renin-producing granular cells under the activation of LXR-alpha. ${ }^{101}$ However, because renin is the first enzymatic and rate-limiting step of the RAS, and LXR-alpha is considered central to the pathophysiology of dyslipidemia, the link between RAS and LXR-alpha in MSCs $^{102}$ further complicates the relationship between MSC adipogenesis and the comorbidities of obesity. Further concentrated research on the relationship between MSC adipogenesis and the comorbidities of obesity is needed to evaluate the potential of effective and safe MSC-based therapies for obesity.

\section{EPIGENETICS IN THE RELATIONSHIP BETWEEN MSC ADIPOGENESIS AND OBESITY}

There has been increasing interest in the role epigenetics plays in obesity development. ${ }^{3,103}$ Epigenetic mechanisms affect gene function without modifying the DNA sequence. ${ }^{103}$ In addition to the classical epigenetic mechanisms including DNA methylation and histone modification, microRNAs (miRNAs) comprising species of short noncoding RNA that regulate gene expression post-transcriptionally, have emerged as important epigenetic players. ${ }^{104}$ For example, Chen et al ${ }^{105}$ reported that the level of miR-146b increased during adipogenesis from human MSCs to mature adipocytes, and further showed the adipogenesis promotion by gain- and loss- 
of-function studies. In addition, Ahn et al ${ }^{106}$ demonstrated that in vivo knockdown of miR-146b by a locked nucleic acid miR-146b antagomir significantly reduced fat volume and body weight in obese mice. These data suggest that miR-146b could be a potential target for treating obesity. Li et al ${ }^{107}$ also showed the promotion of adipogenesis by miR-17-5p and miR-106a in human adipose-derived MSCs by gain- and lossof-function studies, while Shi et al ${ }^{108}$ suggested miR-148a as a potential biomarker of obesity, by showing increased levels of this miRNA in adipose tissue of obese people and mice fed a high-fat diet. Gain- and loss-of-function studies by the latter group also showed that miR-148a accelerated adipogenesis in human adipose-derived MSCs, and that this miRNA acted by suppressing its target gene, Wnt1, suggesting miR-148a promotes MSC adipogenesis through the repression of Wnt1 signaling. ${ }^{108}$ The same group recently reported miRNA microarray data showing differential expression in mature adipocytes compared with human adipose-derived MSCs that suggested potential therapeutic targets for controlling obesity. ${ }^{109}$

Regarding the classical epigenetic mechanisms, Noer et $a l^{110}$ examined the DNA methylation status of adipogenic and non-adipogenic genes in human adipose-derived MSCs, and found that the adipogenic gene promotors were hypomethylated in MSCs, whereas non-adipogenic promotors were methylated. However, DNA methylation reflected neither transcriptional status nor potential for gene expression upon differentiation, suggesting that DNA methylation might not be the sole determinant of adipogenic potential and could constitute a molecular signature of MSCs. ${ }^{110}$ On the other hand, Zhao et all11 investigated whether DNA methylation and histone acetylation at the C/EBP-alpha promoter are involved in MSC adipogenesis using bone marrow-derived MSCs from the glucocorticoid-induced osteoporosis (GIO) mouse model, in which adipogenic potential exceeds osteogenic potential. These authors observed DNA hypomethylation, high PPAR-gamma binding, low histone deacetylase binding, and histone hyperacetylation in the $-1286 \mathrm{bp} /-1065 \mathrm{bp}$ region of the C/EBP-alpha promoter in MSCs from GIO mice compared with normal mice, suggesting DNA methylation and histone acetylation status on the C/EBP-alpha promoter as markers of adipogenic potential in MSCs. ${ }^{111}$ Furthermore, Hemming et al ${ }^{112}$ demonstrated the vital role of histone methylation and demethylation by Enhancer of Zeste homology 2 and lysine demethylase $6 \mathrm{~A}$ in adipogenesis of human bone marrowderived MSCs using overexpression, siRNA knockdown, and enzymatic inhibition.

Epigenetics is a rapidly evolving area of research, and there is still much to be learned before we fully understand the epigenetic mechanisms at play in MSC adipogenesis and obesity. ${ }^{113}$ Further studies are expected to open possibilities for a new level of therapeutic options for obesity.

\section{COMPLEXITY OF MSC ADIPOGENESIS AS A POTENTIAL THERAPEUTIC TARGET FOR OBESITY}

Obesity is a medical condition involving the excess accumulation of adipose tissue; however, simply inhibiting adipogenesis is not a practical strategy to manage obesity. Imbalance between energy intake and expenditure must also be acknowledged. Producing new adipocytes might prevent the increase in large insulin-resistant adipocytes. Therefore, requisite adipogenesis exists. On the other hand, Rieusset et al $^{114}$ reported that decreasing PPAR-gamma activity, either by treatment with a PPAR-gamma-specific antagonist or by invalidation of one allele of the PPAR-gamma gene, protected mice from high-fat diet-induced adipocyte hypertrophy and insulin resistance. It is thus possible that decreased PPARgamma expression in adipose tissue improves insulin sensitivity, as demonstrated in PPAR-gamma-deficient mice ${ }^{115,116}$ or by using a PPAR-gamma-specific antagonist. ${ }^{114}$ Nevertheless, it remains contentious as to the effects of PPARgamma activity, its agonist, and its antagonist on insulin sensitivity. ${ }^{114-118}$ Balanced adipogenesis based on energy intake and expenditure seems to be important.

A relationship between MSCs and ectopic lipid accumulation in insulin-responsive tissues is another complicated issue. For example, skeletal muscle is considered the main destination for insulin-stimulated glucose disposal. ${ }^{119,120}$ To this end, Jacob et al ${ }^{121}$ showed that intramyocellular lipid content was increased in insulin-resistant offspring of type 2 diabetic subjects compared with insulin-sensitive control subjects and suggested that increased intramyocellular lipid accumulation might contribute to the defective glucose uptake in the skeletal muscle of insulin-resistant subjects. In addition, ectopic lipid accumulation in liver is also associated with insulin resistance, ${ }^{122-124}$ and ectopic lipid accumulation in pancreas could contribute to beta-cell dysfunction and a negative association between pancreatic fat and insulin secretion. ${ }^{125-127}$ MSC adipogenesis in adipose tissue could have a role in decreasing ectopic lipid accumulation; however, MSCs also exist in skeletal muscle, liver, and pancreas, and MSC adipogenesis in such tissues further complicates this context. $^{128-131}$ Uezumi et al ${ }^{132}$ identified mesenchymal progenitors in the muscle interstitium and demonstrated that only these cells among the muscle-derived cell populations exhibited efficient adipogenic differentiation both in vitro and in vivo, suggesting that these cells are responsible for ectopic fat cell formation in skeletal muscle. Although the relationship between MSCs and ectopic lipid accumulation remains largely unknown, this link is an area deserving more research.

Finally, brown and white adipocytes are also complicated though important topics (Figure 2). Adipose tissue is traditionally classified as either white adipose tissue (WAT) or brown adipose tissue (BAT). ${ }^{133}$ WAT functions to store excess energy, whereas BAT is involved in thermogenesis and energy expenditure. ${ }^{133}$ Because of this unique thermogenic capacity of BAT resulting from the expression of uncoupling 


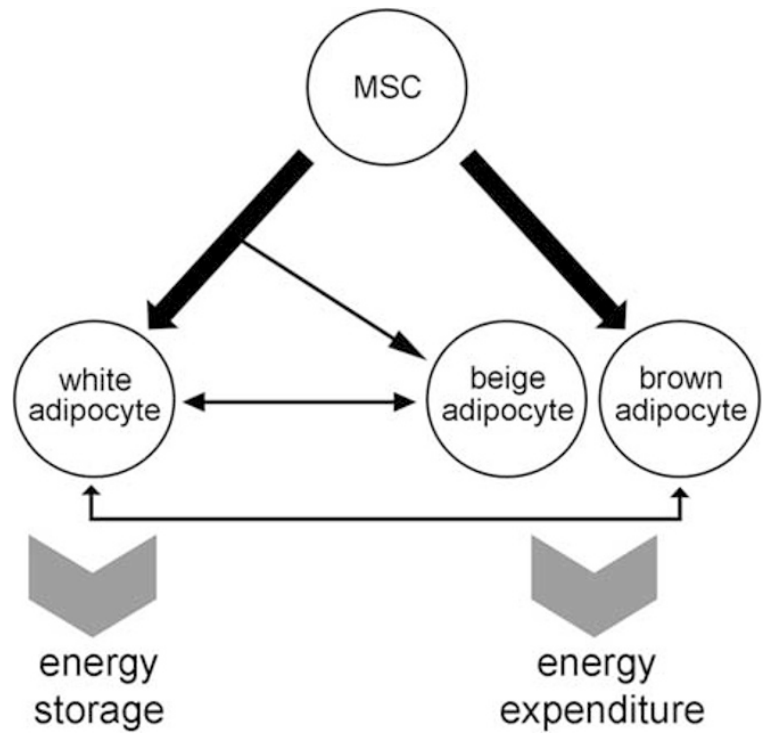

Figure 2 Schematic diagram of white, brown, and beige adipogenesis. Adipocytes differentiated from mesenchymal stem cells (MSCs) are traditionally classified as either white adipocytes or brown adipocytes. White adipocytes play a key role in energy storage, whereas brown adipocytes are specialized for energy expenditure. Of note, recent studies suggest that a third type of adipocytes, namely beige adipocytes, with similar functions to those of brown adipocytes and possibly transdifferentiated from mature white adipocytes or white precursors. Reversible transdifferentiation between white and beige adipocytes, and between white and brown adipocytes are also suggested.

protein 1 in the mitochondrial inner membrane, ${ }^{134}$ BAT activation-regeneration in animal models were studied and reported to improve obesity and insulin resistance. ${ }^{135-139}$ More importantly, recent studies suggest that another type of brown adipocytes, called beige or bright adipocytes, with similar functions to those of brown adipocytes could be recruited in WAT upon environmental stimulation and/or pharmacologic treatment (Figure 2). ${ }^{134,140}$ Among these, García-Alonso et al ${ }^{141,142}$ reported prostaglandin E2 as a key regulator of white-to-brown adipogenesis, while Schulz et $\mathrm{al}^{143}$ showed that $\mathrm{Sca}-1^{+}$adipogenic progenitor cells from murine subcutaneous white fat were highly inducible to differentiate into brown-like adipocytes upon stimulation with BMP7. In addition, Rosenwald et al ${ }^{144}$ demonstrated that cold-induced bright or beige adipocytes in mice were reversed into white adipocytes on warm adaptation and that those white adipocytes converted into bright adipocytes on additional cold stimulation. Reversible transdifferentiation between white and beige adipocytes, and between white and brown adipocytes are suggested. ${ }^{144-146}$ On the other hand, Wang et al ${ }^{147}$ reported that cold exposure induced beige adipocytes as de novo adipogenesis in subcutaneous fat from mice. Taken together, these data indicate that beige adipogenesis combining MSCs in WAT is a promising research area of fat biology expected to identify new therapeutic strategies for obesity.

\section{FUTURE DIRECTIONS AND CONCLUSION}

In terms of future research, identification and thorough characterization of the transcriptional regulators that control MSC adipogenesis is a vital first step. To this end, current and future genome-wide studies are promising tools that could help to answer many of the remaining questions. Second, understanding how the epigenetics of MSC adipogenesis plays a role in obesity needs to progress. Epigenetics is a rapidly evolving area of research with recent miRNA expression profiling studies during MSC adipogenesis revealing several miRNAs with a specific expression pattern. The challenge for future studies is the gain key insights into the epigenetic regulatory mechanisms governing MSC adipogenesis with the potential to provide novel therapeutic targets. Third, the effects of MSC therapies on the comorbidities of obesity must be further studied. The relationship between MSC adipogenesis and such comorbidities remains obscure, and an in-depth understanding is necessary to properly evaluate the potential of effective and safe MSC-based therapeutic strategies for obesity. Finally, future research into the molecular control of brown or beige adipogenesis could lead to a novel breakthrough. Interventions such as controlling brown adipogenesis from MSCs and/or white-to-brown adipogenesis could form the basis of future therapeutic strategies. Importantly, obesity is a heterogeneous group of conditions with multiple causes including genetic and environmental factors. Identification and characterization of different obese phenotypes in further research including emerging fields such as epigenetics are important in the quest for individualized therapeutic strategies for patients with obesity. In the future, it is possible that MSCs may be used to control adipogenesis and/or the comorbidities of obesity individually as an anti-obesity treatment in clinical practice.

In conclusion, MSCs are a promising therapeutic option for obesity in the future and further studies will hopefully elucidate the mechanisms at play in the relationship between MSC adipogenesis and obesity, leading ultimately to novel MSC-based therapeutic options for patients.

\section{ACKNOWLEDGMENTS}

This work was supported, in part, by grants from the Japan Society for the Promotion of Science (KAKENHI 26461086; to KM) and the Kyorin University School of Medicine (No. B102090002; to KM).

\section{DISCLOSURE/CONFLICT OF INTEREST}

The authors declare no conflict of interest.

1. Kopelman PG. Obesity as a medical problem. Nature 2000;404: 635-643.

2. Narayanaswami V, Dwoskin LP. Obesity: current and potential pharmacotherapeutics and targets. Pharmacol Ther 2017;170: 116-147.

3. van Dijk SJ, Molloy PL, Varinli $\mathrm{H}$, et al. Epigenetics and human obesity. Int J Obes 2015;39:85-97.

4. $\mathrm{Ng} \mathrm{M}$, Fleming $\mathrm{T}$, Robinson $\mathrm{M}$, et al. Global, regional, and national prevalence of overweight and obesity in children and adults during 1980-2013: a systematic analysis for the Global Burden of Disease Study 2013. Lancet 2014;384:766-781. 
5. Bianchini F, Kaaks R, Vainio H. Overweight, obesity, and cancer risk. Lancet Oncol 2002;3:565-574.

6. Renehan AG, Tyson M, Egger M, et al. Body-mass index and incidence of cancer: a systematic review and meta-analysis of prospective observational studies. Lancet 2008;371:569-578.

7. Petry NM, Barry D, Pietrzak $\mathrm{RH}$, et al. Overweight and obesity are associated with psychiatric disorders: results from the National Epidemiologic Survey on Alcohol and Related Conditions. Psychosom Med 2008;70:288-297.

8. Simon GE, Von Korff M, Saunders K, et al. Association between obesity and psychiatric disorders in the US adult population. Arch Gen Psychiatry 2006;63:824-830.

9. Batsis JA, Sarr MG, Collazo-Clavell ML, et al. Cardiovascular risk after bariatric surgery for obesity. Am J Cardiol 2008;102:930-937.

10. Heneghan HM, Meron-Eldar S, Brethauer SA, et al. Effect of bariatric surgery on cardiovascular risk profile. Am J Cardiol 2011;108: 1499-1507.

11. Sjostrom $L$, Lindroos $A K$, Peltonen $M$, et al. Lifestyle, diabetes, and cardiovascular risk factors 10 years after bariatric surgery. $\mathrm{N}$ Engl J Med 2004;351:2683-2693.

12. Torquati A, Wright $\mathrm{K}$, Melvin W, et al. Effect of gastric bypass operation on Framingham and actual risk of cardiovascular events in class II to III obesity. J Am Coll Surg 2007;204:776-782.

13. Brook CG, Lloyd JK, Wolf OH. Relation between age of onset of obesity and size and number of adipose cells. Br Med J 1972;2:25-27.

14. Faust IM, Johnson PR, Stern JS, et al. Diet-induced adipocyte number increase in adult rats: a new model of obesity. Am J Physiol 1978;235: E279-E286.

15. Hirsch J, Batchelor B. Adipose tissue cellularity in human obesity. Clin Endocrinol Metab 1976;5:299-311.

16. Crossno JT Jr, Majka SM, Grazia T, et al. Rosiglitazone promotes development of a novel adipocyte population from bone marrowderived circulating progenitor cells. J Clin Invest 2006;116:3220-3228.

17. De Ugarte DA, Morizono K, Elbarbary A, et al. Comparison of multilineage cells from human adipose tissue and bone marrow. Cells Tissues Organs 2003;174:101-109.

18. Lee $\mathrm{RH}, \mathrm{Kim} \mathrm{B}, \mathrm{Choi}$ l, et al. Characterization and expression analysis of mesenchymal stem cells from human bone marrow and adipose tissue. Cell Physiol Biochem 2004;14:311-324.

19. Zuk PA, Zhu M, Mizuno $\mathrm{H}$, et al. Multilineage cells from human adipose tissue: implications for cell-based therapies. Tissue Eng 2001;7:211-228.

20. Rubin CT, Capilla E, Luu YK, et al. Adipogenesis is inhibited by brief, daily exposure to high-frequency, extremely low-magnitude mechanical signals. Proc Natl Acad Sci USA 2007;104:17879-17884.

21. Pittenger MF, Mackay AM, Beck SC, et al. Multilineage potential of adult human mesenchymal stem cells. Science 1999;284:143-147.

22. Ullah I, Subbarao RB, Rho GJ. Human mesenchymal stem cells - current trends and future prospective. Biosci Rep 2015;35: e00191.

23. Le Blanc K, Frassoni F, Ball L, et al. Mesenchymal stem cells for treatment of steroid-resistant, severe, acute graft-versus-host disease: a phase II study. Lancet 2008;371:1579-1586.

24. Kebriaei $P$, Isola $L$, Bahceci $E$, et al. Adult human mesenchymal stem cells added to corticosteroid therapy for the treatment of acute graftversus-host disease. Biol Blood Marrow Transplant 2009;15:804-811.

25. El-Badri NS, Maheshwari A, Sanberg PR. Mesenchymal stem cells in autoimmune disease. Stem Cells Dev 2004;13:463-472.

26. Tolar J, Le Blanc K, Keating A, et al. Concise review: hitting the right spot with mesenchymal stromal cells. Stem Cells 2010;28:1446-1455.

27. Lalu MM, Mclntyre L, Pugliese $C$, et al. Safety of cell therapy with mesenchymal stromal cells (SafeCell): a systematic review and meta-analysis of clinical trials. PLoS ONE 2012;7:e47559.

28. Laudes M. Role of WNT signalling in the determination of human mesenchymal stem cells into preadipocytes. J Mol Endocrinol 2011;46:R65-R72.

29. Ali AT, Hochfeld WE, Myburgh R, et al. Adipocyte and adipogenesis. Eur J Cell Biol 2013;92:229-236.

30. James AW. Review of signaling pathways governing MSC osteogenic and adipogenic differentiation. Scientifica 2013;2013:684736.

31. Muruganandan S, Roman AA, Sinal CJ. Adipocyte differentiation of bone marrow-derived mesenchymal stem cells: cross talk with the osteoblastogenic program. Cell Mol Life Sci 2009;66:236-253.
32. Rosen ED, MacDougald OA. Adipocyte differentiation from the inside out. Nat Rev Mol Cell Biol 2006;7:885-896.

33. Lefterova MI, Lazar MA. New developments in adipogenesis. Trends Endocrinol Metab 2009;20:107-114.

34. Rosen ED, Walkey CJ, Puigserver $P$, et al. Transcriptional regulation of adipogenesis. Genes Dev 2000;14:1293-1307.

35. Frith J, Genever P. Transcriptional control of mesenchymal stem cell differentiation. Transfus Med Hemother 2008;35:216-227.

36. Rosen ED, Spiegelman BM. Molecular regulation of adipogenesis. Annu Rev Cell Dev Biol 2000;16:145-171.

37. Kubota $\mathrm{N}$, Terauchi $\mathrm{Y}$, Miki H, et al. PPAR gamma mediates high-fat diet-induced adipocyte hypertrophy and insulin resistance. Mol Cell 1999;4:597-609.

38. Rosen ED, Sarraf $P$, Troy $A E$, et al. PPAR gamma is required for the differentiation of adipose tissue in vivo and in vitro. Mol Cell 1999;4: 611-617.

39. Moseti D, Regassa A, Kim WK. Molecular regulation of adipogenesis and potential anti-adipogenic bioactive molecules. Int J Mol Sci 2016;17:E124.

40. Ramji DP, Foka P. CCAAT/enhancer-binding proteins: structure, function and regulation. Biochem J 2002;365:561-575.

41. Darlington GJ, Ross SE, MacDougald OA. The role of C/EBP genes in adipocyte differentiation. J Biol Chem 1998;273:30057-30060.

42. Wu Z, Rosen ED, Brun R, et al. Cross-regulation of C/EBP alpha and PPAR gamma controls the transcriptional pathway of adipogenesis and insulin sensitivity. Mol Cell 1999:3:151-158.

43. Rosen ED, Hsu CH, Wang $\mathrm{X}$, et al. C/EBPalpha induces adipogenesis through PPARgamma: a unified pathway. Genes Dev 2002;16:22-26.

44. Fu M, Sun $T$, Bookout $A L$, et al. A nuclear receptor atlas: 3T3-L1 adipogenesis. Mol Endocrinol 2005;19:2437-2450.

45. Ross SE, Erickson RL, Gerin I, et al. Microarray analyses during adipogenesis: understanding the effects of Wnt signaling on adipogenesis and the roles of liver $X$ receptor alpha in adipocyte metabolism. Mol Cell Biol 2002;22:5989-5999.

46. Davis LA, Zur Nieden NI. Mesodermal fate decisions of a stem cell: the Wnt switch. Cell Mol Life Sci 2008;65:2658-2674.

47. Satija NK, Gurudutta GU, Sharma S, et al. Mesenchymal stem cells: molecular targets for tissue engineering. Stem Cells Dev 2007;16: 7-23.

48. Bennett CN, Ross SE, Longo KA, et al. Regulation of Wnt signaling during adipogenesis. J Biol Chem 2002;277:30998-31004.

49. Ross SE, Hemati N, Longo KA, et al. Inhibition of adipogenesis by Wnt signaling. Science 2000;289:950-953.

50. Longo KA, Wright WS, Kang $S$, et al. Wnt10b inhibits development of white and brown adipose tissues. J Biol Chem 2004;279:35503-35509.

51. Christodoulides C, Laudes M, Cawthorn WP, et al. The Wnt antagonist Dickkopf- 1 and its receptors are coordinately regulated during early human adipogenesis. J Cell Sci 2006;119:2613-2620.

52. Wright WS, Longo KA, Dolinsky VW, et al. Wnt10b inhibits obesity in ob/ob and agouti mice. Diabetes 2007:56:295-303.

53. Pospisilik JA, Schramek D, Schnidar H, et al. Drosophila genome-wide obesity screen reveals hedgehog as a determinant of brown versus white adipose cell fate. Cell 2010;140:148-160.

54. Suh JM, Gao X, McKay J, et al. Hedgehog signaling plays a conserved role in inhibiting fat formation. Cell Metab 2006;3:25-34.

55. Fontaine $C$, Cousin W, Plaisant $M$, et al. Hedgehog signaling alters adipocyte maturation of human mesenchymal stem cells. Stem Cells 2008;26:1037-1046.

56. Cousin W, Dani C, Peraldi P. Inhibition of the anti-adipogenic Hedgehog signaling pathway by cyclopamine does not trigger adipocyte differentiation. Biochem Biophys Res Commun 2006;349: 799-803.

57. Cousin W, Fontaine C, Dani C, et al. Hedgehog and adipogenesis: fat and fiction. Biochimie 2007:89:1447-1453.

58. Margoni A, Fotis L, Papavassiliou AG. The transforming growth factor-beta/bone morphogenetic protein signalling pathway in adipogenesis. Int J Biochem Cell Biol 2012;44:475-479.

59. Santibanez JF, Kocic J. Transforming growth factor-beta superfamily, implications in development and differentiation of stem cells. Biomol Concepts 2012;3:429-445.

60. Ignotz RA, Massague J. Type beta transforming growth factor controls the adipogenic differentiation of 3T3 fibroblasts. Proc Natl Acad Sci USA 1985;82:8530-8534. 
61. Zhou S, Eid K, Glowacki J. Cooperation between TGF-beta and Wnt pathways during chondrocyte and adipocyte differentiation of human marrow stromal cells. J Bone Miner Res 2004;19:463-470.

62. Zamani N, Brown CW. Emerging roles for the transforming growth factor-\{beta\} superfamily in regulating adiposity and energy expenditure. Endocr Rev 2011;32:387-403.

63. Gori F, Thomas T, Hicok KC, et al. Differentiation of human marrow stromal precursor cells: bone morphogenetic protein-2 increases OSF2/CBFA1, enhances osteoblast commitment, and inhibits late adipocyte maturation. J Bone Miner Res 1999;14:1522-1535.

64. Ahrens $M$, Ankenbauer $T$, Schroder $D$, et al. Expression of human bone morphogenetic proteins-2 or -4 in murine mesenchymal progenitor C3H10T1/2 cells induces differentiation into distinct mesenchymal cell lineages. DNA Cell Biol 1993;12:871-880.

65. Hata K, Nishimura R, lkeda F, et al. Differential roles of Smad1 and p38 kinase in regulation of peroxisome proliferator-activating receptor gamma during bone morphogenetic protein 2-induced adipogenesis. Mol Biol Cell 2003;14:545-555.

66. Neumann K, Endres M, Ringe J, et al. BMP7 promotes adipogenic but not osteo-/chondrogenic differentiation of adult human bone marrow-derived stem cells in high-density micro-mass culture. J Cell Biochem 2007;102:626-637.

67. Tang QQ, Otto TC, Lane MD. Commitment of $\mathrm{C} 3 \mathrm{H} 10 \mathrm{~T} 1 / 2$ pluripotent stem cells to the adipocyte lineage. Proc Natl Acad Sci USA 2004;101: 9607-9611.

68. Wabitsch $\mathrm{M}$, Hauner $\mathrm{H}$, Heinze $\mathrm{E}$, et al. The role of growth hormone/ insulin-like growth factors in adipocyte differentiation. Metabolism 1995:44:45-49.

69. Holzenberger M, Hamard G, Zaoui R, et al. Experimental IGF-I receptor deficiency generates a sexually dimorphic pattern of organ-specific growth deficits in mice, affecting fat tissue in particular. Endocrinology 2001;142:4469-4478.

70. Hossain P, Kawar B, El Nahas M. Obesity and diabetes in the developing world-a growing challenge. N Engl J Med 2007;356: 213-215.

71. Eckel RH, Kahn SE, Ferrannini E, et al. Obesity and type 2 diabetes: what can be unified and what needs to be individualized? Diabetes Care 2011;34:1424-1430.

72. Dhanasekaran $M$, Indumathi S, Harikrishnan $R$, et al. Human omentum fat-derived mesenchymal stem cells transdifferentiates into pancreatic islet-like cluster. Cell Biochem Funct 2013;31:612-619.

73. Moshtagh PR, Emami SH, Sharifi AM. Differentiation of human adipose-derived mesenchymal stem cell into insulin-producing cells: an in vitro study. J Physiol Biochem 2013;69:451-458.

74. Timper K, Seboek D, Eberhardt M, et al. Human adipose tissue-derived mesenchymal stem cells differentiate into insulin, somatostatin, and glucagon expressing cells. Biochem Biophys Res Commun 2006;341: 1135-1140.

75. Ohmura $Y$, Tanemura $M$, Kawaguchi $N$, et al. Combined transplantation of pancreatic islets and adipose tissue-derived stem cells enhances the survival and insulin function of islet grafts in diabetic mice. Transplantation 2010;90:1366-1373.

76. Fumimoto $\mathrm{Y}$, Matsuyama $\mathrm{A}$, Komoda $\mathrm{H}$, et al. Creation of a rich subcutaneous vascular network with implanted adipose tissuederived stromal cells and adipose tissue enhances subcutaneous grafting of islets in diabetic mice. Tissue Eng Part C Methods 2009;15: 437-444.

77. Dave SD, Vanikar AV, Trivedi HL, et al. Novel therapy for insulindependent diabetes mellitus: infusion of in vitro-generated insulin-secreting cells. Clin Exp Med 2015;15:41-45.

78. Liu GY, Liu J, Wang YL, et al. Adipose-derived mesenchymal stem cells ameliorate lipid metabolic disturbance in mice. Stem Cells Transl Med 2016:5:1162-1170.

79. Jakobsson T, Treuter E, Gustafsson JA, et al. Liver X receptor biology and pharmacology: new pathways, challenges and opportunities. Trends Pharmacol Sci 2012;33:394-404.

80. Janowski BA, Willy PJ, Devi TR, et al. An oxysterol signalling pathway mediated by the nuclear receptor LXR alpha. Nature 1996;383: 728-731.

81. Kidani $Y$, Bensinger SJ. Liver $X$ receptor and peroxisome proliferatoractivated receptor as integrators of lipid homeostasis and immunity. Immunol Rev 2012;249:72-83.
82. Peet DJ, Turley SD, Ma W, et al. Cholesterol and bile acid metabolism are impaired in mice lacking the nuclear oxysterol receptor LXR alpha. Cell 1998;93:693-704.

83. Steffensen KR, Gustafsson JA. Putative metabolic effects of the liver $X$ receptor (LXR). Diabetes 2004;53(Suppl 1):S36-S42.

84. Tobin KA, Steineger HH, Alberti $\mathrm{S}$, et al. Cross-talk between fatty acid and cholesterol metabolism mediated by liver $X$ receptor-alpha. Mol Endocrinol 2000;14:741-752.

85. Gao M, Liu D. The liver X receptor agonist T0901317 protects mice from high fat diet-induced obesity and insulin resistance. AAPS J 2013;15:258-266.

86. Juvet LK, Andresen SM, Schuster GU, et al. On the role of liver $X$ receptors in lipid accumulation in adipocytes. Mol Endocrinol 2003;17:172-182.

87. Soukas A, Socci ND, Saatkamp BD, et al. Distinct transcriptional profiles of adipogenesis in vivo and in vitro. J Biol Chem 2001;276: 34167-34174.

88. Steffensen KR, Schuster GU, Parini P, et al. Different regulation of the LXRalpha promoter activity by isoforms of CCAAT/enhancer-binding proteins. Biochem Biophys Res Commun 2002;293:1333-1340.

89. Willy PJ, Umesono $\mathrm{K}$, Ong ES, et al. LXR, a nuclear receptor that defines a distinct retinoid response pathway. Genes Dev 1995;9: 1033-1045.

90. Matsushita K, Morello F, Zhang Z, et al. Nuclear hormone receptor LXRalpha inhibits adipocyte differentiation of mesenchymal stem cells with Wnt/beta-catenin signaling. Lab Invest 2016;96:230-238.

91. Beaven SW, Matveyenko A, Wroblewski K, et al. Reciprocal regulation of hepatic and adipose lipogenesis by liver $\mathrm{X}$ receptors in obesity and insulin resistance. Cell Metab 2013;18:106-117.

92. Kalaany NY, Gauthier KC, Zavacki AM, et al. LXRs regulate the balance between fat storage and oxidation. Cell Metab 2005;1:231-244.

93. Landsberg L, Aronne LJ, Beilin LJ, et al. Obesity-related hypertension: pathogenesis, cardiovascular risk, and treatment-a position paper of the The Obesity Society and The American Society of Hypertension. Obesity 2013;21:8-24.

94. Jiang SZ, Lu W, Zong XF, et al. Obesity and hypertension. Exp Ther Med 2016;12:2395-2399.

95. Marketou ME, Parthenakis Fl, Kalyva A, et al. Increased mobilization of mesenchymal stem cells in patients with essential hypertension: the effect of left ventricular hypertrophy. J Clin Hypertens 2014;16:883-888.

96. Dzau VJ. Circulating versus local renin-angiotensin system in cardiovascular homeostasis. Circulation 1988;77:14-113.

97. Dzau VJ. Local expression and pathophysiological role of reninangiotensin in the blood vessels and heart. Basic Res Cardiol 1993;88 (Suppl 1):1-14.

98. Matsushita $\mathrm{K}, \mathrm{Wu} \mathrm{Y}$, Okamoto $\mathrm{Y}$, et al. Local renin angiotensin expression regulates human mesenchymal stem cell differentiation to adipocytes. Hypertension 2006:48:1095-1102.

99. Matsushita $\mathrm{K}, \mathrm{Wu} \mathrm{Y}$, Pratt RE, et al. Blockade of angiotensin II type 2 receptor by PD123319 inhibits osteogenic differentiation of human mesenchymal stem cells via inhibition of extracellular signalregulated kinase signaling. J Am Soc Hypertens 2015;9:517-525.

100. Matsushita K, Wu Y, Pratt RE, et al. Deletion of angiotensin II type 2 receptor accelerates adipogenesis in murine mesenchymal stem cells via Wnt10b/beta-catenin signaling. Lab Invest 2016;96:909-917.

101. Matsushita K, Morello F, Wu Y, et al. Mesenchymal stem cells differentiate into renin-producing juxtaglomerular (JG)-like cells under the control of liver X receptor-alpha. J Biol Chem 2010;285: 11974-11982.

102. Matsushita K, Zhang Z, Pratt RE, et al. Molecular mechanism of juxtaglomerular cell hyperplasia: a unifying hypothesis. J Am Soc Hypertens 2007;1:164-168.

103. Herrera BM, Keildson S, Lindgren CM. Genetics and epigenetics of obesity. Maturitas 2011;69:41-49.

104. Sato F, Tsuchiya S, Meltzer SJ, et al. MicroRNAs and epigenetics. FEBS J 2011;278:1598-1609.

105. Chen L, Dai YM, Ji CB, et al. MiR-146b is a regulator of human visceral preadipocyte proliferation and differentiation and its expression is altered in human obesity. Mol Cell Endocrinol 2014;393:65-74.

106. Ahn J, Lee $\mathrm{H}$, Jung $\mathrm{CH}_{\text {, et }}$ al. MicroRNA-146b promotes adipogenesis by suppressing the SIRT1-FOXO1 cascade. EMBO Mol Med 2013;5: 1602-1612. 
107. Li H, Li T, Wang $\mathrm{S}$, et al. miR-17-5p and miR-106a are involved in the balance between osteogenic and adipogenic differentiation of adipose-derived mesenchymal stem cells. Stem Cell Res 2013;10: 313-324.

108. Shi C, Zhang M, Tong M, et al. miR-148a is associated with obesity and modulates adipocyte differentiation of mesenchymal stem cells through Wnt signaling. Sci Rep 2015;5:9930.

109. Shi C, Huang F, Gu X, et al. Adipogenic miRNA and meta-signature miRNAs involved in human adipocyte differentiation and obesity. Oncotarget 2016;7:40830-40845.

110. Noer A, Sorensen AL, Boquest AC, et al. Stable CpG hypomethylation of adipogenic promoters in freshly isolated, cultured, and differentiated mesenchymal stem cells from adipose tissue. Mol Biol Cell 2006;17:3543-3556.

111. Zhao QH, Wang SG, Liu SX, et al. PPARgamma forms a bridge between DNA methylation and histone acetylation at the C/EBPalpha gene promoter to regulate the balance between osteogenesis and adipogenesis of bone marrow stromal cells. FEBS J 2013;280: 5801-5814.

112. Hemming S, Cakouros D, Isenmann S, et al. EZH2 and KDM6A act as an epigenetic switch to regulate mesenchymal stem cell lineage specification. Stem Cells 2014;32:802-815.

113. Ozkul Y, Galderisi U. The impact of epigenetics on mesenchymal stem cell biology. J Cell Physiol 2016;231:2393-2401.

114. Rieusset J, Touri F, Michalik L, et al. A new selective peroxisome proliferator-activated receptor gamma antagonist with antiobesity and antidiabetic activity. Mol Endocrinol 2002;16:2628-2644.

115. Jones JR, Barrick C, Kim KA, et al. Deletion of PPARgamma in adipose tissues of mice protects against high fat diet-induced obesity and insulin resistance. Proc Natl Acad Sci USA 2005;102:6207-6212.

116. Miles PD, Barak Y, He W, et al. Improved insulin-sensitivity in mice heterozygous for PPAR-gamma deficiency. J Clin Invest 2000;105: 287-292.

117. Olefsky JM. Treatment of insulin resistance with peroxisome proliferatoractivated receptor gamma agonists. J Clin Invest 2000;106:467-472.

118. Yamauchi T, Kamon J, Waki H, et al. The mechanisms by which both heterozygous peroxisome proliferator-activated receptor gamma (PPARgamma) deficiency and PPARgamma agonist improve insulin resistance. J Biol Chem 2001;276:41245-41254.

119. Lim S, Meigs JB. Links between ectopic fat and vascular disease in humans. Arterioscler Thromb Vasc Biol 2014;34:1820-1826.

120. Phillips DI, Caddy S, Ilic V, et al. Intramuscular triglyceride and muscle insulin sensitivity: evidence for a relationship in nondiabetic subjects. Metabolism 1996:45:947-950.

121. Jacob S, Machann J, Rett K, et al. Association of increased intramyocellular lipid content with insulin resistance in lean nondiabetic offspring of type 2 diabetic subjects. Diabetes 1999;48:1113-1119.

122. Galbo T, Shulman GI. Lipid-induced hepatic insulin resistance. Aging 2013;5:582-583.

123. Lim S. Ectopic fat assessment focusing on cardiometabolic and renal risk. Endocrinol Metab 2014;29:1-4.

124. Sattar N, Gill JM. Type 2 diabetes as a disease of ectopic fat? BMC Med 2014;12:123.

125. Heni M, Machann J, Staiger $H$, et al. Pancreatic fat is negatively associated with insulin secretion in individuals with impaired fasting glucose and/or impaired glucose tolerance: a nuclear magnetic resonance study. Diabetes Metab Res Rev 2010;26:200-205.

126. Hocking S, Samocha-Bonet $\mathrm{D}$, Milner $\mathrm{KL}$, et al. Adiposity and insulin resistance in humans: the role of the different tissue and cellular lipid depots. Endocr Rev 2013;34:463-500.
127. Tushuizen ME, Bunck MC, Pouwels PJ, et al. Pancreatic fat content and beta-cell function in men with and without type 2 diabetes. Diabetes Care 2007;30:2916-2921.

128. da Silva Meirelles L, Chagastelles PC, Nardi NB. Mesenchymal stem cells reside in virtually all post-natal organs and tissues. J Cell Sci 2006;119:2204-2213.

129. Davani B, Ikonomou L, Raaka BM, et al. Human islet-derived precursor cells are mesenchymal stromal cells that differentiate and mature to hormone-expressing cells in vivo. Stem Cells 2007;25: 3215-3222.

130. Jackson WM, Nesti $\amalg$, Tuan RS. Potential therapeutic applications of muscle-derived mesenchymal stem and progenitor cells. Expert Opin Biol Ther 2010:10:505-517.

131. Pan Q, Fouraschen SM, Kaya FS, et al. Mobilization of hepatic mesenchymal stem cells from human liver grafts. Liver Transpl 2011;17:596-609.

132. Uezumi A, Fukada S, Yamamoto N, et al. Mesenchymal progenitors distinct from satellite cells contribute to ectopic fat cell formation in skeletal muscle. Nat Cell Biol 2010;12:143-152.

133. Park A, Kim WK, Bae KH. Distinction of white, beige and brown adipocytes derived from mesenchymal stem cells. World J Stem Cells 2014;6:33-42.

134. $\mathrm{Fu} J$, Li Z, Zhang $\mathrm{H}$, et al. Molecular pathways regulating the formation of brown-like adipocytes in white adipose tissue. Diabetes Metab Res Rev 2015;31:433-452.

135. Enerback $\mathrm{S}$, Jacobsson $\mathrm{A}$, Simpson $\mathrm{EM}$, et al. Mice lacking mitochondrial uncoupling protein are cold-sensitive but not obese. Nature 1997:387:90-94.

136. Kopecky J, Clarke G, Enerback S, et al. Expression of the mitochondrial uncoupling protein gene from the aP2 gene promoter prevents genetic obesity. J Clin Invest 1995;96:2914-2923.

137. Kozak LP, Anunciado-Koza R. UCP1: its involvement and utility in obesity. Int J Obes 2008;32(Suppl 7):S32-S38.

138. Poher AL, Altirriba J, Veyrat-Durebex $C$, et al. Brown adipose tissue activity as a target for the treatment of obesity/insulin resistance. Front Physiol 2015;6:4.

139. Roman S, Agil A, Peran $\mathrm{M}$, et al. Brown adipose tissue and nove therapeutic approaches to treat metabolic disorders. Transl Res 2015;165:464-479.

140. Wang W, Seale P. Control of brown and beige fat development. Nat Rev Mol Cell Biol 2016;17:691-702.

141. Garcia-Alonso V, Claria J. Prostaglandin E2 signals white-to-brown adipogenic differentiation. Adipocyte 2014;3:290-296.

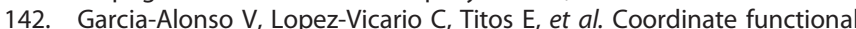
regulation between microsomal prostaglandin $E$ synthase-1 (mPGES-1) and peroxisome proliferator-activated receptor gamma (PPARgamma) in the conversion of white-to-brown adipocytes. J Biol Chem 2013:288:28230-28242.

143. Schulz TJ, Huang TL, Tran TT, et al. Identification of inducible brown adipocyte progenitors residing in skeletal muscle and white fat. Proc Natl Acad Sci USA 2011;108:143-148.

144. Rosenwald M, Perdikari A, Rulicke $\mathrm{T}$, et al. Bi-directional interconversion of brite and white adipocytes. Nat Cell Biol 2013;15:659-667.

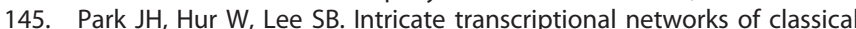
brown and beige fat cells. Front Endocrinol 2015;6:124.

146. Cinti S. Transdifferentiation properties of adipocytes in the adipose organ. Am J Physiol Endocrinol Metab 2009;297:E977-E986.

147. Wang QA, Tao C, Gupta RK, et al. Tracking adipogenesis during white adipose tissue development, expansion and regeneration. Nat Med 2013;19:1338-1344 